\title{
Pipeline for COPD drugs flows with combination candidates
}

On 26 July, a key committee in the European Medicines Agency gave the thumbs up to Novartis's QVA149, the first of a handful of combination drugs aimed at chronic obstructive pulmonary disease (COPD). Such combination therapies face a very crowded market, but developers say that the products are more convenient for patients and show clinical promise for reducing symptoms of the illness, such as breathlessness and blockage of the airways by mucus.

David Morris, global head of development for primary care at Novartis, headquartered in Basel, Switzerland, is optimistic. "What we're seeing with this combination is really an additive benefit," he says. "It's a fundamental insight into how to treat COPD."

As a disease that can result from multiple risk factors, including smoking, COPD ranks fifth among the world's leading causes of death, afflicting more than 65 million people globally. Those numbers are expected only to rise. "It's an enormous market," says Milo Puhan, who directs the University of Zurich's Institute of Social and Preventive Medicine. "These people take these drugs every day," says Puhan, adding that the medications "cost maybe between one and four dollars daily. It's a very sizable number."

Symptoms of COPD range from breathlessness to bronchitis flare-ups that can land a patient in the hospital's intensive care unit. But, it's the long-term decline in the elasticity of lung tissue that leads to decreased lung function. Depending on the severity of the case, physicians treat the disease with bronchodilators, corticosteroids, oxygen and other therapies. The QVA149 combination, which will be marketed as the Ultibro Breezhaler, involves two bronchodilators, which open airways through different mechanisms: indacaterol, a longacting beta ${ }_{2}$-adrenergic agonist (LABA) that stimulates the receptors in smooth muscle; and glycopyrronium, a long-acting muscarinic antagonist (LAMA) that blocks the nerve signals that constrict those muscles. According to a study published on 18 July in Respiratory Medicine, QVA149 is relatively safe and has minimal or moderate adverse effects ${ }^{1}$.

The type of green light given by the EMA's Committee for Medicinal Products for Human Use (CHMP) to QVA149 in July typically leads to EU marketing approval within three months. As such, the drug will have an advantage in that region, notes Clive Page, a pharmacologist at King's College London. "If they're first to market that can be a good thing.

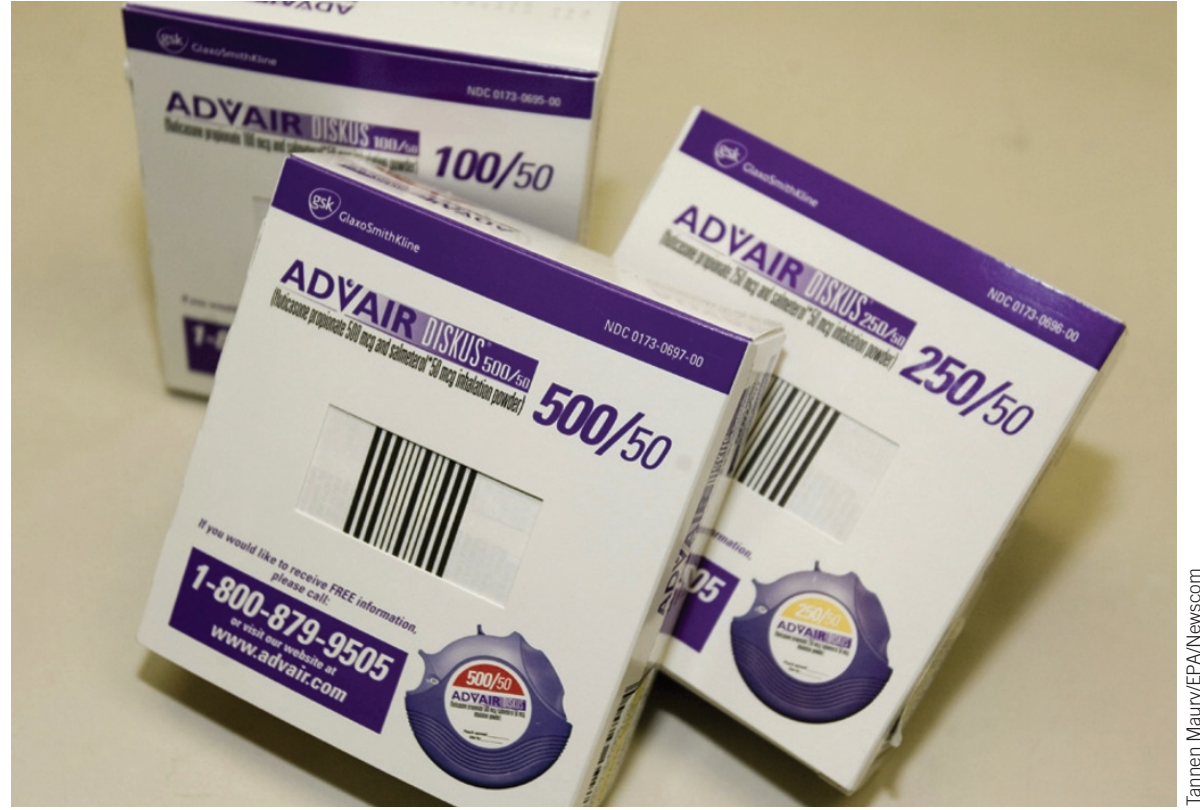

Breathless speculation: New drugs may affect the market dominated by products such as Advair.

You're going to have to fight harder with a new combination to say why you're better," he says, referring to the other companies that have once-daily LABA/LAMA products moving forward in their pipelines. These include Boehringer Ingelheim, based in Ingelheim am Rhein, Germany; GlaxoSmithKline (GSK), headquartered in London; and Almirall, based in Barcelona.

Individual bronchodilators improve lung function-measured as forced expiratory volume in one second (FEV1) - by about 50\%, estimates Morris, whereas LABA/LAMA products can double that improvement ${ }^{2}$. These new combination drugs also appear to boost FEV1 better than older combinations such as GSK's Advair, which mixes the LABA salmeterol with the inhaled corticosteroid fluticasone to reduce inflammatory response ${ }^{3}$. "These drugs really work, and the affect size is much larger, much greater than other types of combinations that we've had," says James Donohue, a pulmonologist at the University of North Carolina at Chapel Hill.

\section{Prescription for change?}

Changing the prescription habits of clinicians and patients will be a huge hurdle. "When do you use an enhanced steroid in the regimen, and when do you use a LABA/LAMA? I think that's the big million-dollar question now," says Nicola Hanania, a pulmonary clinician at the Baylor College of Medicine in Houston. For now, there is some speculation that symptomatic patients with shortness of breath or difficulty exercising may benefit more from LABA/LAMAs early on, says Hanania. Patients with severe COPD who are already taking a host of therapies are unlikely to see a difference.

The question of which LABA/LAMA products will survive in the long term may come down to who has the best marketing and the best inhaler, according to Page: "I think it's going to be difficult otherwise to distinguish between the different combinations."

Makers of LABA/LAMA products are keen to set themselves apart from the crowd. For example, Pearl Therapeutics, a Redwood City, California-based biotech firm acquired in June by the UK's AstraZeneca, has a twicedaily LABA/LAMA in phase 3 development. The company distinguishes its product on the basis of its use of microscopic lipid particles that bind to the compounds to keep them separate from each other and the walls of the inhaler, helping to ensure a more accurate dose.

Despite the challenges LABA/LAMAs face, most experts are cautiously optimistic. "It's very positive because these drugs are very potent and very active," says Page. "But, what we really need to see are some new classes, I think, that can add further bronchodilation on top of that."

Helen Thompson

1. Dahl, R. et al. Respir. Med. http://doi.org/njj (2013).

2. Bateman, E.D. et al. Euro. Respir. J. http://doi.org/njm (2013).

3. Vogelmeier, C.F. et al. Lancet Respir. Med. 1, 51-60 (2013). 